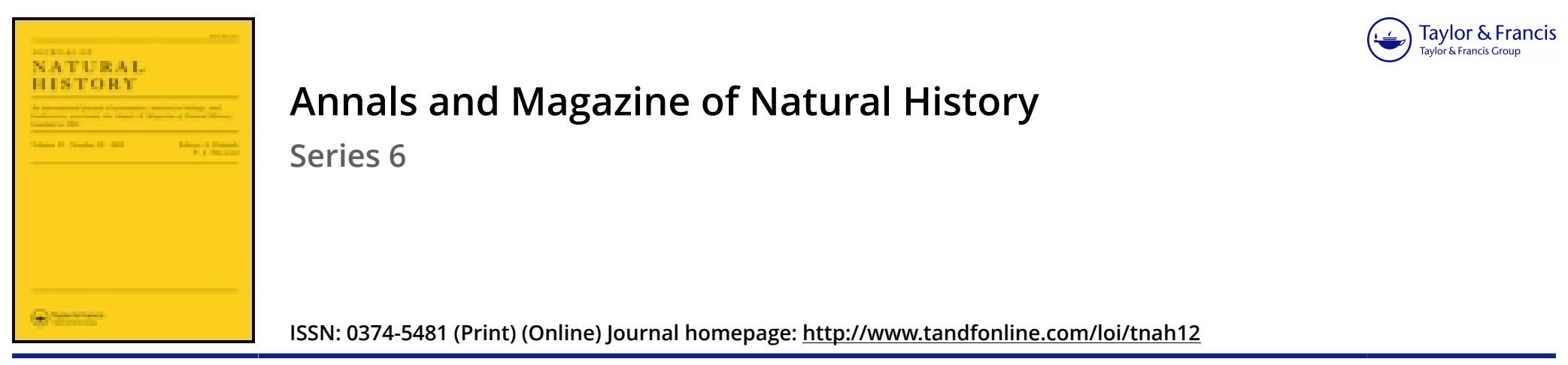

\title{
XXXVII._On a reptilian tooth with two roots
}

\section{H.G. Seeley F.R.S.}

To cite this article: H.G. Seeley F.R.S. (1893) XXXVII._On a reptilian tooth with two roots, Annals and Magazine of Natural History, 12:69, 227-230, DOI: 10.1080/00222939308677609

To link to this article: http://dx.doi.org/10.1080/00222939308677609

$$
\text { 曲 Published online: } 06 \text { Oct } 2009 .
$$

Submit your article to this journal ๔

Q View related articles $₫$ 


\section{EXPLANATION OF PLATE IV.}

Fig. 1. Body of animal from above, somewhat flattened.

Fig. 2. Ditto from the side.

Fig. 3. ILead viewed from the left front. $a . a=$ first antennæ.

Fig. 4. Last segment of abdomen from below.

Fig. 5. Abdomen from below, showing the opercular plates.

Fig. 6. One of the legs.

\section{XXXVII.-On a Reptilian Tooth with two Roots. By H. G. SeELeY, F.R.S.}

THE division of the root of a mammalian tooth into two or more portions has been regarded as a convenient means of predicating mammalian organization for the animal in which this condition is found, notwithstanding the circumstance that in diverse groups of mammals the rost is not divided in any of the teeth, and that in mammals the division is absent from the incisors and almost all canines.

Professor Marsh, in 1890, figured, in the 'American Journal of Science,' teeth of the animal which he named Triceratops, in which two roots certainly occur, but placed transversely, as sometimes happens among the wider posterior molar teeth of mamnals. It is not improbable that this division, as American palæontologists have suggested, is apparent rather than real, and has been produced by absorption of the tooth in wear, by the successional tooth rising beneath it, since the form of the excavation between the roots exactly corresponds to the form of the crown. In any case, the condition in this American fossil, by whatever name the genus may be eventually known, was unparalleled among Reptilia, though in a few mammals with two roots to a posterior molar tooth those roots are arranged transversely.

In 1854 (Quart. Journ. Geol. Soc. vol. x. p. 420) the late Sir Richard Owen tigured a Purbeck fossil from bed K.93 in Austen's guide, under the name Nwthetes destructor. It was then described as a pleurodont lizard allied tomonitors of the genus Varanus; and figs. $2 d$ and $e(l . c$.$) are representations$ of teeth in the jaw which have the aspect of possessing two roots arranged in the antero-posterior direction. This condition is further evidenced by the enlargement of the tooth $d$ given in fig. 4, though no word occurs in the text referring to the structure; so that it is probably only a pit or groove at the base of the crown. With these fragments of jaw the author 
associated a tibia and fibula, indicating long and slender hind legs; but I am not aware of any evidence of association, and am disposed to refer the limb-bones to the crocodilian genus Theriosuchus. On at least three other occasions references were made to these teeth. In the Palæontographical Society's volume for 1861 they are said to be like teeth of Megalosaurus, finely serrated back and front, and attached by partial anchylosis to the inner side of an alveolar wall. Of this character I have not seen any evidence; but I have not had the opportunity of examining the original specimens. In 1854 Nuthetes was said to differ from Megalosaurus in showing no trace of alveolar divisions for the teeth. This may be quite true, and yet not bear the construction that the teeth were not in sockets, for the bones of the jaw are extremely thin and have a denseness and thinness which are only known in bones of Ornithosauria and Saurischian reptiles, and genera like Aristosuchus. Sir Richard Owen further states that the thickest part of the crown is not the middle, but is nearer the anterior border, as in Varanus and Megalosaurus.

In Sir R. Owen's 'Palæontology' the known facts are summarized and the fossil grouped under the Lacertilia (second ed., 1861, p. 307) and described as a carnivorous or insectivorous lizard.

Subsequently, in the Palæontographical Society's volume for 1879, further remains discovered by Mr. Beckles are figured (pl. ii.) and described. The genus is grouped with the Crocodilia, and the teeth (p. 16) are said to show an excavation or longitudinal depression on the side of the base. In the British Museum Catalogue of Foss. Rept. pt. i., 1888, $\mathrm{Mr}$. Lydekker groups the genus as "ordinal position uncertain," placing it after the animals which are massed together as Dinosauria, and remarking that the teeth are more like those of dinosaurs than lizards.

'The jaws indicate a very small animal, being (as stated by Sir R. Owen) in the fragments preserved only 6 lines deep, while the largest fragment of jaw is $1 \frac{1}{2}$ inch long. I have no doubt, if ordinal affinities can be inferred from teeth, that these animals are Saurischian and nearly allied to Streptospondylus, Megalosaurus, and Aristosuchus. The teeth are essentially diminutive forms of a Megalosaur. This identification is based upon the shape of the crown, the condition of its surface-enamel, the serrations at the anterior and posterior margins of the crown, and the general form of the root, which, however, is shorter than in Mlegalosaurus; and the comparison would probably be closer with Streptospondylus, to 
which genus I should be disposed to refer the teeth from Cuckfield, for which Mr. Lydekker has suggested the name Megalosaurus Oweni. It is interesting that the dwarf carnivorous Saurischian Nuthetes should be associated with a dwarf Ornithischian, Echinodon, allied by its teeth to Scelidosaurus, and to that genus I should refer the dermal bones, termed granicones, which were associated by Sir R. Owen with Nuthetes.

There being obvious points of resemblance between the Saurischia and the Anomodontia, in the possession of similar skeletal elemerits which approximate to those of mammals, it has seemed worth recording that in the British Museum, among the twelve isolated teeth of Nuthetes and two fragments of jaw obtained with the Beckles collection, is a single tooth which distinctly shows two roots in anterior and posterior positions. This tooth is 7 millim. long, has lost its enamel, and therefore shows no trace of the characteristic marginal serrations. It exactly corresponds in form to the anterior teeth in Owen's original figure, and widens from the apex to the base of the roots, where it is 4 millim. wide. The height of the crown is 4 millim., its side is flattened; there is a medial area slightly depressed, with slightly elevated lateral ridges back and front, which exactly correspond with those upon the typical teeth of $N u$. thetes. Below the crown the tooth divides into two slightly divergent roots, which are 3 millim. long; and the posterior root may be slightly the larger. Each root is channelled on the side by a shallow depression similar to that which usually extends down the sides of the single-rooted teeth of Nuthetes and Megalosaurus. 'The roots are well-defined and marked with slight wavy concentric lines of growth, similar to those which frequently occur upon the roots of teeth placed in sockets, and not unlike the transverse enamelwaves on the crowns. The roots narrow slightly towards their

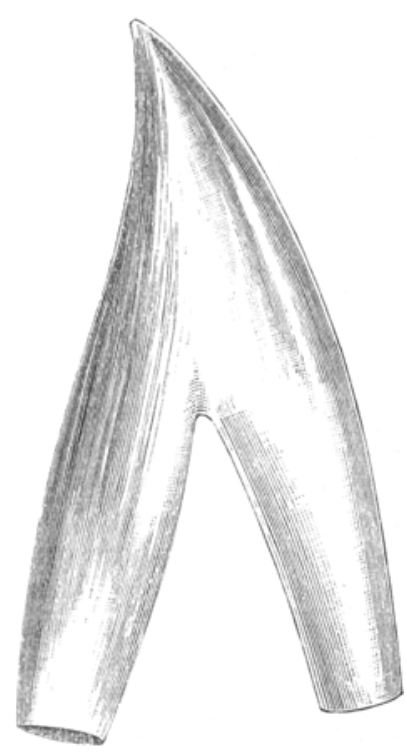

Tooth of Nuthetes. . Brit. Mus. No. $48208 . \times 10$. extremities; thie posterior root 
appears to be fractured near its termination, where it indicates a pulp-cavity, though the inner and outer walls are compressed close together. 'The roots are about 1 millim. wide. Notwithstanding a certain resemblance in form of the interspace between the roots to the form of the crown, [ do not see any ground for affirming that it has been produced by absorption. It is, however, certain that the character is an abnormal one, since it is abseut from the other isolated teeth, and its chief interest consists in showing that it is possible for a reptile to develop roots to a tooth of the mammalian molar type; so that if this abnormal condition, seen in Nuthetes, were normal and general in a fossil jaw, it would constitute an important deviation from the reptilian dentition.

The figure is ten times natural size.

\section{XXXVIII-Descriptions of Two new North-Bornean Mammuls. By Oldfield Thomas.}

\section{[Plate VII.]}

\section{Semnopithecus sabanus, sp. n. (Pl. VII.)}

Body, arms and legs, and tail grey; hands and feet black, as in the group to which $S$. Hosei, $S$. Everetti, and $S$. Thomasi belong.

Forehead with a high median black crest, commencing immediately bebind the centre of the brow-ridges; the hairs of the crest stand up vertically and are about an inch and a half in length. Eyebrow-bristles long, black, projected forwards over the eyes; behind them, on each side of the central crest, the forehead-hairs lie back flat against the head and are whitish in colour over the whole crown. Outside these whitish patches, again, the sides of the face, from the orbits to the ears, are quite black, and the hairs of the occiput are also decidedly darker, especially terminally, than are those of the pale frontal patches. It results from this arrangement of the colours that on looking down vertically on the crown one sees a pale frontal area, bisected mesially by the blackish crest and surrounded on all sides by black, in front by the black eyebrows, laterally by the black temples, and posteriorly by the black tipped occipital hairs. These crown 